\title{
New applications of planctomycetes: feeding and colouring of Daphnia
}

\section{Opinion}

In the last years we joined efforts in a productive collaboration, a microbiologist and an ecotoxicologist, where we decided to put together the microcrustacean Daphnia spp. and the pink bacteria from the phylum Planctomycetes.

Daphnia spp. are organisms commonly used in aquatic ecotoxicology experiments and extensively used to assess water environmental quality. In lentic freshwater ecosystems Daphnia has a varied diet since it is a non-selective filter feeder. They ingest all small suspended particles such as algae, bacteria, ciliates, and flagellates as well as detritus and particulate organic matter. ${ }^{1}$ However, when Daphnia spp. reared in laboratory, they are generally fed exclusively on microalgae, a single food and carbon source. ${ }^{2,3}$ This food regime is already discussed as nutritional scarce for a good performance of Daphnia spp..$^{1-5}$ In laboratory experiments is essential to guarantee that Daphnia (standard organism) are in excellent conditions in order to respond only to the stress which are in study. So increase the diversity of food sources and nutritional quality is a concern for researchers to assure that Daphnia are in the greatest food and reproductive conditions life-history.

In order to answer to this concern, we decided to perceive if bacteria could be used as food or supplement to the usual food and improve the life history of Daphnia. Planctomycetes are ubiquitous bacteria whose role in the various habitats where they dwell is still not known, and may be a food source for other trophic levels in the web chain. These bacteria have unique morphological, genetic, metabolic and physiological identity. ${ }^{6}$ Their complex cell plan, their budding reproduction without the intervention of the FtZ universal prokaryotic division protein and other characteristics shared with eukaryotes like the ability to synthesize sterols make them remarkable and worthwhile for interesting and imaginative studies. Many of the isolated planctomycetes are pink pigmented and in particular Rhodopirellula rubra, a species isolated from the biofilm of macroalgae in the North coast of Portugal, possesses a strong pink to reddish colour.

Feeding Daphnia spp. with R. rubra showed us that this bacterium supplied in adequate quantities seems to be able to provide Daphnia with many of its nutritional needs. However, when R. rubra was added in supplement to the microalga Raphidocelis subcapitata, Daphnia life-history parameters are significant improved ${ }^{2,3}$ as also observed with $S$. cereviseae ${ }^{7}$. In special, the reproductive capacity, i.e., increase of offspring when this two food and carbon source were provided. Furthermore, the colourless Daphnia become well pigmented as well as their offspring. We found these results very interesting and promptly stimulated us to continue with new and innovative ideas of research, namely for aquaculture applications.

Now we know that Planctomycetes are edible by other organism in the web chain and can be metabolized in a way that their pigments
Volume 7 Issue 3 - 2018

Olga Maria Lage, Sara C.Antunes
University of Porto, Faculty of Sciences, Portugal

Correspondence: Olga Maria Lage, Assistant Professor, University of Porto, Faculty of Sciences, Portugal,Tel +35 I220402724, Email olga.lage@fc.up.pt

Received: April II, 2018 | Published: May 03, 2018

are incorporated but not degraded. These bacteria may be used as single-cell-pigment in analogy to the single-cell-protein or even both. Moreover, although in an unknown way, they have the capacity to improve fertility. Is this only viable for Daphnia or other organisms may benefit from Planctomycetes? With these characteristics we envisage a great potential for applications of Planctomycetes in food and pharmaceutical industry. However, we have still a very long but exciting way to go.

\section{Acknowledgements}

None.

\section{Conflict of interest}

The author declares there is no conflict of interest.

\section{References}

1. Ebert D. Ecology, Epidemiology, and Evolution of Parasitism in Daphnia. Bethesda (MD): National Library of Medicine (US), National Center for Biotechnology Information. 2005.

2. Antunes SC, Almeida RA, Carvalho T, et al. Feasibility of planctomycetes as a nutritional or supplementary food source for Daphnia spp. Ann Limnol Int J Lim. 2016;52:317-325.

3. Marinho MC, Lage OM, Catita J, et al. Adequacy of planctomycetes as supplementary food source for Daphnia magna. Antonie van Leeuwenhoek. 2017.

4. Freese HM, Martin-Creuzburg D. Food quality of mixed bacteriaalgae diets for Daphnia magna. Hydrobiologia.2013;715(1):63-76.

5. Buratini S, Aragão M. Food supplement in Daphnia similis and Ceriodaphnia dubia cultures: effects of yeast and feed digestion. Ecotoxicol Environ Contam. 2012;7(1):21-26.

6. Lage OM, Bondoso J. Planctomycetes and macroalgae, a striking association. Frontiers in Microbiology. 2014;5:267.

7. Otero A, Munoz M, Medina-Robles V, et al. Effect of food intake on productive variables of two species of cladocera, under laboratory conditions. Revista MVZ Cordoba. 2013;18:3642-3647. 